\title{
Sociocultural and psychological determinants in migrants for noncompliance with occlusion therapy for amblyopia
}

\author{
Angela M. Tjiam • Hilal Akcan • Fatma Ziylan • Elizabet Vukovic • \\ Sjoukje E. Loudon • Caspar W. N. Looman • Jan Passchier • Huibert J. Simonsz
}

Received: 26 May 2010 /Revised: 17 January 2011 / Accepted: 11 February 2011 / Published online: 12 March 2011

(C) The Author(s) 2011. This article is published with open access at Springerlink.com

\begin{abstract}
Background Compliance with occlusion therapy for amblyopia in children is low when their parents have a low level of education, speak Dutch poorly, or originate from another country. We determined how sociocultural and psychological determinants affect compliance.
\end{abstract}

Ms. H. Akcan and Ms. F. Ziylan contributed equally to this work.

Electronic supplementary material The online version of this article (doi:10.1007/s00417-011-1637-5) contains supplementary material, which is available to authorized users.

A. M. Tjiam $(\triangle) \cdot$ E. Vukovic $\cdot$ S. E. Loudon $\cdot$ H. J. Simonsz Department of Ophthalmology, Room EE-1607, Erasmus MC, University Medical Center Rotterdam,

PO Box 2040, 3000 CA Rotterdam, The Netherlands e-mail: amtjiam@gmail.com

H. Akcan · F. Ziylan

Department of Health - Orthoptics,

HU University of Applied Sciences Utrecht,

Bolognalaan 101,

3584 CH Utrecht, The Netherlands

C. W. N. Looman

Department of Public Health, Erasmus MC, University Medical Center Rotterdam,

PO Box 2040, 3000 CA Rotterdam, The Netherlands

J. Passchier

Department of Medical Psychology, Erasmus MC,

University Medical Center Rotterdam,

PO Box 2040, 3000 CA Rotterdam, The Netherlands

J. Passchier

Department of Psychology and Education,

VU University Amsterdam,

Van der Boechorststraat 1,

1081 BT Amsterdam, The Netherlands
Methods Included were amblyopic children between the ages of 3 and 6, living in low socio-economic status (SES) areas. Compliance with occlusion therapy was measured electronically. Their parents completed an oral questionnaire, based on the "Social Position \& Use of Social Services by Migrants and Natives" questionnaire that included demographics and questions on issues like education, employment, religion and social contacts. Parental fluency in Dutch was rated on a five-point scale. Regression analysis was used to describe the relationship between the level of compliance and sociocultural and psychological determinants.

Results Data from 45 children and their parents were analyzed. Mean electronically measured compliance was $56 \pm 44$ percent. Children whose parents had close contact with their neighbors or who were highly dependent on their family demonstrated low levels of compliance. Children of parents who were members of a club and who had positive conceptualizations of Dutch society showed high levels of compliance. Poor compliance was also associated with low income, depression, and when patching interfered with the child's outdoor activity. Religion was not associated with compliance.

Conclusions Poor compliance with occlusion therapy seems correlated with indicators of social cohesion. High social cohesion at micro level, i.e., family, neighbors and friends, and low social cohesion on macro level, i.e., Dutch society, are associated with noncompliance. However, such parents tend to speak Dutch poorly, so it is difficult to determine its actual cause.

Keywords Amblyopia - Ethnic groups · Patient compliance $\cdot$ Social cohesion $\cdot$ Social class 


\section{Introduction}

Amblyopia, a "lazy eye", is a preventable, unilateral loss of vision and affects approximately $3-4 \%[1,2]$ of the population. Recovery is possible by occluding the better eye with a patch for several hours a day, generally before the age of 6 [3]. Despite amblyopia treatment, approximately one-third [2] of the affected children do not attain a visual acuity in the amblyopic eye to be able to read ( 0.5 decimals [4]). This is primarily caused by poor compliance with occlusion therapy, i.e., the eye is not patched according to the orthoptist's prescription $[5,6]$. In a previous study, we found that noncompliance with occlusion therapy correlated strongly with the parents' country of origin, poor parental fluency in the national language, and low levels of education [6]. It may be possible, however, that other factors related to the country of origin, such as religion, cultural integration, perspective on health, and culture, also play a role in the degree of compliance.

Immigrants encounter several difficulties once they arrive in the host country. They may not speak the language of the host country, may have had limited education, may be in a poor financial state, may be unemployed, may lack suitable accommodation, often have no social network, may have different cultural norms and religious beliefs; they must comply with new laws, as well as cope with possible racism and other exclusionary behavior. These difficulties can be problematic when visiting a physician, resulting in miscommunication and possible noncompliance with treatment [610]. In addition, immigrant patients' views on health and disease may differ from those of native patients [7, 8, 10, 11].

In the Netherlands, approximately one-fifth of the total population is non-native [12]. In Amsterdam, 49\% of the population is of non-native origin; in Rotterdam and The Hague, $47 \%$ is non-native, and $31 \%$ of the population in Utrecht is non-native [12]. Most non-native inhabitants of these cities are first-generation immigrants, and live in ethnically diverse, low-SES, suburban neighborhoods [12].

Among these inhabitants, immigrant-related determinants other than country of origin, fluency in Dutch and level of education may have an effect on the level of compliance with occlusion therapy. For these reasons, we explored whether sociocultural, psychological and differences in acculturation similarly affect compliance with occlusion therapy. We performed this study in ethnically diverse, low-SES, suburban areas of the cities Utrecht and The Hague.

\section{Methods}

The current study was part of a nation-wide pre-post implementation study of compliance-improving measures $[13,14]$, including an educational booklet, containing a wordless cartoon story on the importance of wearing the eye patch and a calendar with reward stickers for the children, and an information leaflet in six languages (Dutch, English, French, German, Turkish and Arabic) for the parents [6]. Nine orthoptists working at an orthoptic department in an ethnically diverse, low-SES, suburban area in one of the four major cities in the Netherlands (Amsterdam, Utrecht, The Hague and Rotterdam) were asked to recruit newly diagnosed amblyopic children between the ages of 3 and 6 years with a visual acuity difference of $\geq 1 \operatorname{LogMAR}$ line between the eyes and an amblyopic factor, and who were to undergo occlusion therapy for the first time.

Compliance was electronically measured by using the Occlusion Dose Monitor (ODM) [15-17]. The ODM is a device that records, every 2 minutes, the difference in temperature between the front and back of the ODM. The parents were asked to attach the ODM to the front of the eye patch with double-sided adhesive tape; hence, the temperature at the back of the device was higher than at its front when the patch with ODM was worn on the eye [6].

For this study, parents of children who received standard treatment (without the compliance-improving measures), living in Utrecht and The Hague, were asked to participate in an oral interview at their home: these interviews were conducted by two members of the research team (HA, FZ).

During the home visit, an extended questionnaire was applied. This structured oral questionnaire is based on a questionnaire which had been developed by the Netherlands Institute for Social Research /SCP and the Institute for Sociologic-Economic Research (ISEO) of the Erasmus University in Rotterdam. This questionnaire had been developed for the research project called SPVA (a Dutch acronym for "Sociale Positie en Voorzieningengebruik Allochtonen en Autochtonen" meaning "Social Position \& Use of Social Services by Migrants and Natives") [18]. Its purpose was to investigate the proportion of inhabitants of different ethnic minorities participating in the Dutch society, educational system and labor market, and to monitor these individuals over a period of several years [19, 20]. Approximately 4,200 households had filled out this questionnaire each year in the years 1988, 1992, 1994, 1996, 1998, 2002 and 2003. For the current study, we used 172 of the 265 questions of the 2002 version of the SPVA questionnaire: questions concerning the educational level and labor of grandparents, aunts and uncles of the child, and questions about previous jobs, periods of unemployment or previous social payments of the parents were omitted. The remaining 172 questions concerned ten domains (e-supplement): Demography, Migration \& Household (e.g., "What is your marital status?"); Education ("What is your highest level 
of education?"); Employment ("What is your current work?"); Income ("What is your gross family income?"); Health ("How is your health in general?"); Language Usage ("Do you experience difficulties with reading, for example, Dutch magazines?"); Religion ("How frequently do you visit religious communities?"); Family Bonds (Statement: "You can always count on your family."); Social Contacts ("Do you have Dutch neighbors / friends who visit you once in a while?"); and Cultural Integration \& Conceptualization (Statement: "The Dutch society is open toward foreign people"). An additional domain Lazy Eye was added to the questionnaire, comprising 33 questions from "The Utility Analysis of Amblyopia" Questionnaire [21], "Children's Visual Function Questionnaire (VFQ) [22] and "Patching Questionnaire"[23] (e-supplement). Most questions could be answered on a 5-point scale ranging from 'Strongly Agree' to 'Strongly Disagree'. The questionnaire was presented to the parents in a face-to-face interview format.

During the home visit, the researchers rated the parent's fluency in Dutch on a five-point-scale [6], with 1 'no fluency'; 2 'scarcely fluent / poor fluency'; 3 'moderate fluency'; 4 'good fluency'; and 5 'near native speaker/ exceptional fluency'. The living conditions of the child were observed using a structured observation list to score the quality of the residence. This list was based on a score sheet used by the Ministry of Housing, Spatial Planning and the Environment to define the quality of a residence [24]. It contained questions such as: on what floor is the residence located, is there an elevator in the building, how many rooms are there in the apartment/house, and how many persons live at the residence. A home visit lasted approximately 2.5 hours.

\section{Statistical analysis}

The initial visual acuity was the visual acuity as measured during the child's first visit to the orthoptic department. Visual acuity was measured using the Landolt-C chart; in younger children (3-4 years) a non-standardized picture chart or the E-chart was used. As non-standardized picture charts were used, visual acuity is indicated in LogMAR instead of absolute values.

The questions, the electronically measured compliance scores obtained from the implementation study, and parental fluency in Dutch were analyzed in SPSS 16.0 for Windows. With univariate general linear regression model analysis, correlations between independent variables, that is, all questions from the questionnaire, and the electronically measured compliance were determinant. Variables with statistical significance were further analyzed in multiple regression analysis. A $P$-value of $<0.05$ indicates statistical significance.
The study was conducted in accordance with the tenets of the Declaration of Helsinki.

\section{Results}

A total of 114 children were recruited in the preimplementation phase of the study in Amsterdam, Rotterdam, Utrecht and The Hague. Of these, 33 lived in Amsterdam or Rotterdam, and, were not eligible because of long travel distances. Parents of 14 other children could not be reached despite two phone calls and two house calls. Fifteen parents refused to participate in the oral interview: the reason they all gave was that they had no time. Of the 52 parents who responded to the interview, 24 had a 'moderate' or 'poor' level of fluency in the Dutch language. Sixteen parents were of Dutch origin, 13 Moroccan, 13 Turkish, and ten had other countries of origin. Seven were Christians, 30 were Muslims, seven had no religion and eight had other religious affiliations. The mean age of the children was $4.84 \pm 1.24$ years when occlusion therapy was started. The mean prescribed occlusion time was 3:37 $\pm 1: 15$ hours a day, for 7 days a week, at the initiation of occlusion therapy. The mean initial visual acuity was $0.42 \mathrm{SD} 0.33$ LogMAR in the amblyopic eye and $0.07 \mathrm{SD} 0.11$ LogMAR in the better eye.

Data on compliance was available for 45 of the 52 children: in seven cases, data were incomplete due to repeated failure of the ODM. Mean compliance was $56 \pm 44$ percent. Compliance followed a bimodal distribution (solid polynomial line in Fig. 1) with two peaks: one at $90 \%$, the other at $0 \%$. Twenty-two of the 45 children occluded less than half of the occlusion time prescribed by the orthoptist (Fig. 1).

Fifty-five of the 205 questions were excluded from analysis: 34 did not apply to or were not answered by the majority of parents and 21 were answered unanimously, $i$. e., all parents answered 'agree' or 'disagree'. Univariate analysis showed that 18 of the remaining 150 variables correlated significantly with the electronically measured compliance. These variables belonged to the domains Income, Health, Family Bonds, Social Contacts, Cultural Integration \& Conceptualization, and Lazy Eye. Table 1 depicts the 18 variables that correlated significantly with the electronically measured compliance.

In the domain Income, low income (i.e., $<€ 1,750$ net/ month, the average income in the Netherlands [25]) was associated with poor compliance $(P=0.017)$.

In the domain Health, children of parents who had experienced periods of depression during the previous four weeks had a significantly lower compliance $(P=0.022)$.

In the domain Family Bonds, two questions were associated with compliance: parents who agreed that 


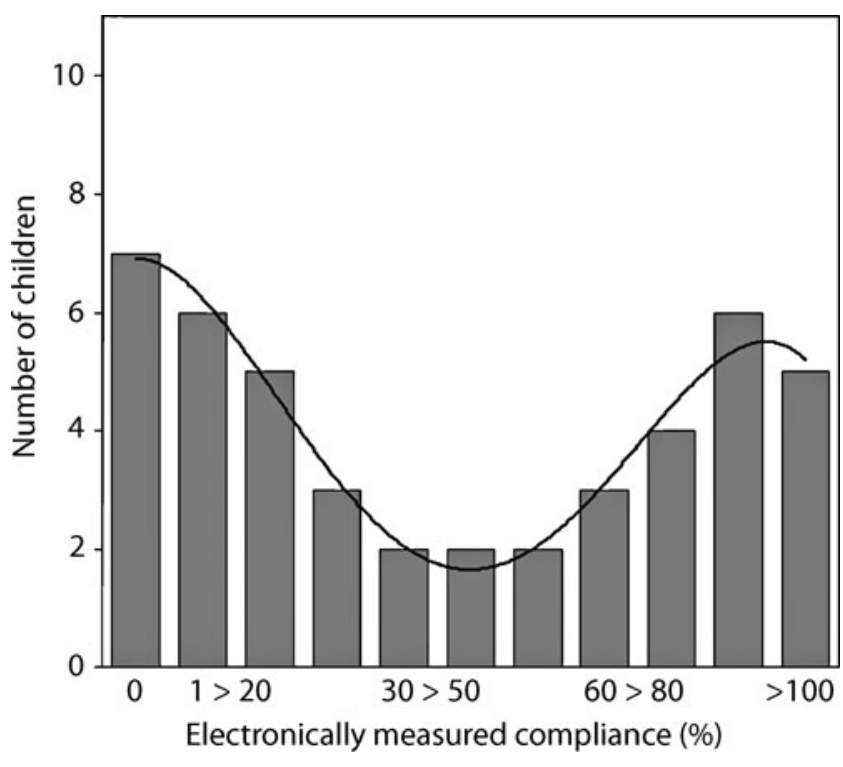

Fig. 1 Bar chart of electronically measured compliance in the study population $(n=45)$. Compliance was defined as the actual occlusion time measured with the ODM divided by the prescribed occlusion time and expressed as a percentage, in which $100 \%$ indicates a compliance of $100 \%$. This graph followed a bimodal distribution with two peaks (solid line)

grandparents should be prepared to babysit their grandchildren on a regular basis, and who agreed that grown-up children, who lived near their parents, should visit them at least once a week, had a lower compliance $(P=0.001$ and $P=0.039$ respectively).

Four questions in the domain Social Contacts demonstrated correlations with compliance: parents who had frequent close contact with neighbors demonstrated poor compliance. Children of parents who were members of a social club, for example, a sports club or a religious organization had high compliance $(P=0.003)$. Parents of 19 children were member of one club; five parents were member of two or more clubs. Twelve parents were member of a religious organization, ten of a sports club, three of a music association or a theatrical company, two of a school association, one of a labor union, and one of a political organization.

In the domain Cultural Integration \& Conceptualization in Table 1, eight questions pertaining negative perceptions of the Dutch society correlated with low compliance: parents who agreed with these questions were significantly less compliant (30\%-40\%) than parents who did not agree with these questions. For example, parents who were of the opinion that it is more important for boys to earn their own money than for girls, that people are getting divorced too easily nowadays and that, in the Netherlands, people speak too openly about sexuality, had a significantly lower compliance ( $P=0.020, P=0.023$, and $P=0.026$ respectively). Poor compliance was also found in parents who found that elderly people should be able to live with their children, that parents should allow their grown-up children to live in their home, and that the elderly family members have more to say when making an important decision than younger family members ( $P=0.014, P=0.026$, and $P=0.005$ respectively).

In the domain Lazy Eye, low compliance correlated with the parental opinion that the child had difficulty with playing outside while wearing the patch $(P=0.007)$. When parents said the child was less active while wearing the patch, compliance was significantly lower $(P=0.046)$.

No questions in the domain "Religion" were found to be associated with compliance. The kind of religion, differences in interest in religion, frequency of practicing the religion, frequency of visiting religious communities (e.g., the church or mosque), and strict or less strict religious beliefs did not affect compliance with occlusion therapy.

The 18 variables that were significant in univariate analysis were included in the multiple regression analysis. One variable remained significant: "In the Netherlands, people speak too openly about sexuality" $(P=0.002)$.

\section{Discussion}

In this group of children from ethnically diverse, low-SES areas, we found that compliance correlated with the degree of integration within Dutch society. Low levels of compliance were associated with close family bonds and close neighbor contacts. Conversely, parents who were member of a club and who had positive conceptualizations of Dutch society had good compliance. Low compliance was also found in case of low income or depression of the parents and when patching interfered with the outdoor activity of the child. Almost half of the children with amblyopia from these ethnically diverse, low-SES areas occluded less for than half of the prescribed occlusion time.

Perception of health status and the utilization of health services differ between native and non-native inhabitants [10, 26-29]. O'Malley et al.[29] and Fassaert et al. [26] found that participation of migrants in their host culture is associated positively with more the use of health care services. Fassaert et al. [26] found that Turkish migrants in the Netherlands who spoke Dutch more fluently consulted medical specialists less often, but utilized mental health services more often. Higher levels of social interaction with Dutch people was related with more utilization of mental health services among Turkish women [26]. However, other studies reported a high utilization of general practice services among patients with low-SES and by non-native patients [10, 27, 28].

In our study, we found a relationship between compliance and the degree of social cohesion within a community or society. Social cohesion describes the degree to which 
Table 1 In univariate analysis, 18 questions were associated with electronically measured compliance with occlusion therapy. On the left, in italics, all domains are listed. All questions that were not significant were omitted. Mean electronically measured compliance in percentage (in brackets is $N$ ) per response on each question is given. $* P<0.01$

\begin{tabular}{|c|c|c|c|c|c|c|}
\hline Domain & \multicolumn{5}{|c|}{ Mean compliance in $\%(N)$} & $P$-value \\
\hline \multicolumn{7}{|l|}{ Demography, Migration \& Household } \\
\hline \multicolumn{7}{|l|}{ Education } \\
\hline \multicolumn{7}{|l|}{ Employment } \\
\hline Income & Yes & No & & & & \\
\hline Family income of $<€ 1,750.00$ net/month & $43.6(27)$ & $77(14)$ & & & & 0.017 \\
\hline Health & Yes & No & Not answered & & & \\
\hline $\begin{array}{l}\text { In the past } 4 \text { weeks, have you experienced } \\
\text { any periods of depression? } \\
\text { Language Usage }\end{array}$ & $35.9(11)$ & $59(30)$ & $82(4)$ & & & 0.047 \\
\hline \multicolumn{7}{|l|}{ Religion } \\
\hline Family Bonds & Strongly agree & Agree & Agree/disagree & Disagree & Strongly disagree & \\
\hline $\begin{array}{l}\text { "Grandparents should be prepared to babysit } \\
\text { their grandchildren on a regular basis" }\end{array}$ & $26.9(9)$ & $45(14)$ & $64(10)$ & $82(12)$ & $-(0)$ & $0.001 *$ \\
\hline $\begin{array}{l}\text { "Grown-up children, who live near their } \\
\text { parents, should visit them at least once } \\
\text { a week" }\end{array}$ & $37.5(9)$ & $54(26)$ & $70(6)$ & $86(4)$ & $-(0)$ & 0.039 \\
\hline Social Contacts & Very well & Good & Moderate & Poor & None & \\
\hline \multirow{2}{*}{$\begin{array}{l}\text { How well do your neighbors interact } \\
\text { with one another? }\end{array}$} & $30.8(11)$ & $63(33)$ & $94(1)$ & $-(0)$ & - $(0)$ & 0.022 \\
\hline & Very unfortunate & Unfortunate & Do not matter & Positive & Very positive & \\
\hline \multirow{2}{*}{$\begin{array}{l}\text { How would you feel if your neighbors } \\
\text { moved away? }\end{array}$} & $30.3(7)$ & $52(24)$ & $74(14)$ & $-(0)$ & $-(0)$ & 0.024 \\
\hline & As little as possible & Greet in passing & Talk once in while & Visit once in a while & Frequent contact & \\
\hline \multirow{2}{*}{$\begin{array}{l}\text { To what degree should neighbors have } \\
\text { contact with one another? }\end{array}$} & $86.3(2)$ & $74(1)$ & $63(20)$ & $51(12)$ & $39(10)$ & 0.019 \\
\hline & Yes & No & Not answered & & & \\
\hline Are you a member of a club? & $71.8(25)$ & $37(19)$ & $1.9(1)$ & & & $0.003 *$ \\
\hline Cultural Integration \& Conceptualization & Strongly agree & Agree & Agree/disagree & Disagree & Strongly disagree & \\
\hline $\begin{array}{l}\text { "It is more important for boys to earn their } \\
\text { own money than for girls" }\end{array}$ & - (0) & $32(11)$ & $44(3)$ & $56(8)$ & $68(23)$ & 0.020 \\
\hline $\begin{array}{l}\text { "Elderly people should be able to live with } \\
\text { their children" }\end{array}$ & $32.3(8)$ & $51(22)$ & $70(11)$ & $88(4)$ & $-(0)$ & 0.014 \\
\hline $\begin{array}{l}\text { "Parents should allow their grown-up } \\
\text { children to live in their home" }\end{array}$ & $30.7(6)$ & $49(19)$ & $67(17)$ & $85(3)$ & $-(0)$ & 0.026 \\
\hline $\begin{array}{l}\text { "Nowadays, people are getting divorced } \\
\text { too easily" }\end{array}$ & $30.3(6)$ & $44(12)$ & $58(12)$ & $72(15)$ & $-(0)$ & 0.023 \\
\hline $\begin{array}{l}\text { "Elderly family members have more to say } \\
\text { when making an important decision than } \\
\text { do younger ones" }\end{array}$ & $-(0)$ & $41(17)$ & $54(6)$ & $66(20)$ & $79(2)$ & $0.005^{*}$ \\
\hline $\begin{array}{l}\text { "In the Netherlands, people speak too } \\
\text { openly about sexuality" }\end{array}$ & $33.5(6)$ & $46(15)$ & $58(8)$ & $71(15)$ & $83(1)$ & 0.033 \\
\hline \multirow{2}{*}{$\begin{array}{l}\text { "Certain sectors of the economy only } \\
\text { keep going because of non-native } \\
\text { employees" }\end{array}$} & $32.3(6)$ & $49(20)$ & $65(13)$ & $81(6)$ & $-(0)$ & 0.026 \\
\hline & Yes & A little & No & Absolutely not & & \\
\hline "Dutch people are reticent" & $28.6(5)$ & $48(20)$ & $67(17)$ & $86(3)$ & & 0.021 \\
\hline Lazy Eye & Strongly agree & Agree & Agree/disagree & Disagree & Strongly disagree & \\
\hline \multirow{2}{*}{$\begin{array}{l}\text { "My child has difficulty playing outside } \\
\text { when he/she wears the patch" }\end{array}$} & $0(1)$ & - (0) & $29(6)$ & $50(16)$ & (22) 70 & $0.007 *$ \\
\hline & (Almost) never & Occasionally & Sometimes & Often & (Almost) always & \\
\hline $\begin{array}{l}\text { "My child is less active when he/she is } \\
\text { being treated" }\end{array}$ & $66.2(24)$ & $51(11)$ & $36(9)$ & $21(1)$ & $-(0)$ & 0.046 \\
\hline
\end{tabular}

human behavior expresses commitment and solidarity within a given community [30]. The degree of social cohesion is linked to social confidence and social trust, is inversely associated with social exclusion, and defines a person's social position within a society [30]. Our findings suggest that the children of parents who have close family bonds and close neighbor contacts (more socially cohered at the micro level) had a significantly lower mean electronically measured compliance. Parents who were members of a club and who had positive conceptualizations 
of Dutch society (more socially cohered at a macro level) had, in general, good electronically measured compliance.

It is difficult to determine the exact cause of noncompliance [8], as the inability to speak Dutch necessitates family bonds and neighbor contacts. Secondly, parents who do not speak Dutch misunderstand the orthoptist's instruction $[6,7,9]$. Similarly, poor fluency in Dutch decreases the chance to find work. Poverty may induce depression [31]. Depressive moods affects social cohesion [32].

We found no evidence that the kind of religion, frequency of practicing the religion, or strict or less strict religious beliefs, had any effect on compliance with occlusion therapy. The role of religion on health care behavior is still unclear: religious behavior may influence health care behavior positively or negatively. In a study among HIV patients, certain religious practices were positively associated with treatment adherence, whereas other religious beliefs played a negative role due to the stigma attached to HIV disease [33]. An earlier report about patients with diabetes mellitus in Sweden [34] suggested that religious differences indirectly affect the degree of selfcare behavior. In that study, Swedes had an active self-care behavior and a healthy and controlled life-style, whereas immigrants from (former) Yugoslavians and Muslims emphasized enjoyment of life and a passive self-care attitude. Although Muslims tended to take their diabetes as 'the will of Allah or God', they searched more actively for information about management of diabetes [34].

Our population of parents who lived in ethnically diverse, low-SES areas is not representative to the general population in the Netherlands. Our study was restricted to 45 children. However, our data collection was highly comprehensive, involving the distribution and recollection of the ODMs and the administration of the comprehensive oral questionnaire, including 205 questions, during home visits. On the other hand, the oral administration of the questionnaire resulted in a $100 \%$ response. In case of a postal questionnaire, the response would have been much lower, not only because of the lengthy questionnaire, but also because some of the participants were not able to read. In case of poor fluency in Dutch, parents were asked to arrange a relative of friend to interpret the questions. In some instances, an informal interpreter had to be approached on the spot (Turkish parents excluded, because both researchers spoke Turkish fluently). Moreover, the researchers tried to minimize language errors by paraphrasing and reconfirming the parents' answers, where necessary.

In conclusion, poor compliance with occlusion therapy was correlated with the degree of integration within the Dutch society and indicators of social cohesion. High social cohesion at micro level, i.e., family, neighbors and friends, and low social cohesion on macro level, i.e., Dutch society, were associated with noncompliance. We do not expect, however, that these findings will cause a change in orthoptic clinics, but it may support orthoptists working in ethnically diverse, low-SES areas in better understanding the compliance behavior of non-native patients. Finally, we believe that good cultural integration of immigrants within the society of their host country seems to be of great importance in achieving better compliance with medical treatment, in general.

Acknowledgements The Occlusion Dose Monitor was developed at the department for Medical Technical Development at the Academical Medical Centre, Amsterdam, the Netherlands in 1996-1997 as a public domain project.

The authors thank Cees Zandvliet for the explanation about the SPVA study, Ellen van Minderhout, Marleen Vermeulen-Jongen, Brigitte Simonsz-Tóth, Arieneke Burger-Meywaard, Marlien Kruyswijk, Sylvia Rousse and Dorien Valster for their help with data collection and efforts in recruiting the children. Acknowledgement for proofreading and correcting the English edition goes[33] to Mrs. K. Verhoef of Verticals Translations \& Administration and Mrs. A. Van Rij-De Jong.

This work was supported by: ZonMw - the Netherlands Organization for Health Research and Development [grant number: \#6320.0008].

Clinical trials registration reference number: ISRCTN22835481/ NTR713 www.trialregister.nl

A part of this study was the graduate thesis of Ms. H. Akcan and Ms. F. Ziylan of the HU University of Applied Sciences Utrecht (Hogeschool Utrecht) the Netherlands, Department of Orthoptics in October 2008.

Conflicts of interest None.

Open Access This article is distributed under the terms of the Creative Commons Attribution Noncommercial License which permits any noncommercial use, distribution, and reproduction in any medium, provided the original author(s) and source are credited.

\section{References}

1. Attebo K, Mitchell P, Cumming R, Smith W, Jolly N, Sparkes R (1998) Prevalence and causes of amblyopia in an adult population. Ophthalmology 105:154-159

2. Groenewoud JH, Tjiam AM, Lantau VK, Hoogeveen WC, de Faber JT, Juttmann RE, de Koning HJ, Simonsz HJ (2010) Rotterdam Amblyopia Screening Effectiveness Study: detection and causes of amblyopia in a large birth cohort. Invest Ophthalmol Vis Sci 51:3476-3484

3. Holmes JM, Clarke MP (2006) Amblyopia. Lancet 367:1343-1351

4. Rahi J, Logan S, Timms C, Russell-Eggitt I, Taylor D (2002) Risk, causes, and outcomes of visual impairment after loss of vision in the non-amblyopic eye: a population-based study. Lancet 360:597-602

5. Smith LK, Thompson JR, Woodruff G, Hiscox F (1995) Factors affecting treatment compliance in amblyopia. J Pediatr Ophthalmol Strabismus 32:98-101

6. Loudon SE, Fronius M, Looman CW, Awan M, Simonsz B, van der Maas PJ, Simonsz HJ (2006) Predictors and a remedy for noncompliance with amblyopia therapy in children measured with the occlusion dose monitor. Invest Ophthalmol Vis Sci 47:4393-4400 
7. Van Wieringen JC, Harmsen JA, Bruijnzeels MA (2002) Intercultural communication in general practice. Eur J Public Health 12:63-68

8. Schouten BC, Meeuwesen L (2006) Cultural differences in medical communication: a review of the literature. Patient Educ Couns 64:21-34

9. Harmsen H, Meeuwesen L, van Wieringen J, Bernsen R, Bruijnzeels M (2003) When cultures meet in general practice: intercultural differences between GPs and parents of child patients. Patient Educ Couns 51:99-106

10. Norredam M, Nielsen SS, Krasnik A (2009) Migrants' utilization of somatic healthcare services in Europe - a systematic review. Eur J Public Health 20:555-563

11. Seeleman C, Suurmond J, Stronks K (2005) Een arts van de wereld. Etnische diversiteit in de medische praktijk [A doctor of the world. Ethnical diversity in medical practice]. Bohn Stafleu van Loghum, Houten

12. Statistics/Netherlands [Population; generation, gender, age, ethnicity and area, 1 January 2010] www.cbs.nl (accessed on 25 January 2010)

13. Tjiam AM, Vukovic E, Asjes-Tydeman WL, Holtslag G, Loudon SE, Sinoo MM, Simonsz HJ (2010) How Dutch orthoptists deal with noncompliance with occlusion therapy for amblyopia. Strabismus 18:146-166

14. Vukovic E, Tjiam A, Asjes-Tydeman W, Loudon S, Sinoo M, Van Agt H, De Koning H, Simonsz H (2008) Non-compliance in occlusion therapy for amblyopia can be improved, but can such measures be implemented nationwide? The Association for Research in Vision and Ophthalmology Conference, Fort Lauderdale (USA). Meet Abstr 49:E-2584

15. Moseley MJ, Fielder AR (1995) Measurement of compliances with occlusion therapy. J Pediatr Ophthalmol Strabismus 32:399-400

16. Chopovska Y, Loudon SE, Cirina L, Zubcov A, Simonsz HJ, Luchtenberg M, Fronius M (2005) Electronic recording of occlusion treatment for amblyopia: potential of the new technology. Graefes Arch Clin Exp Ophthalmol 243:539-544

17. Fielder AR, Irwin M, Auld R, Cocker KD, Jones HS, Moseley MJ (1995) Compliance in amblyopia therapy: objective monitoring of occlusion. Br J Ophthalmol 79:585-589

18. The Netherlands Institute for Social Research SCP [Social Position \& Use of Social Services by Migrants and Natives] www.scp.nl/content.jsp?objectid=default:18718 (accessed on 21 December 2007)

19. Weijters G, Scheepers P (2003) Verschillen in sociale integratie tussen etnische groepen: beschrijving en verklaring [Differences in social integration among ethnic groups: description and explanation]. Mens \& Maatschappij [Human \& Society] 78:144-157

20. Groeneveld S, Weijers-Martens Y (2003) Minderheden in Beeld SPVA-02 [Minorities in the Picture SPVA-02]. ISEO, Rotterdam
21. Van de Graaf ES, Van der Sterre GW, Polling JR, Van Kempen H, Simonsz B, Simonsz HJ (2004) Amblyopia \& Strabismus Questionnaire: design and initial validation. Strabismus 12:181-193

22. Felius J, Stager DR Sr, Berry PM, Fawcett SL, Stager DR Jr, Salomao SR, Berezovsky A, Birch EE (2004) Development of an instrument to assess vision-related quality of life in young children. Am J Ophthalmol 138:362-372

23. Cole SR, Beck RW, Moke PS, Celano MP, Drews CD, Repka MX, Holmes JM, Birch EE, Kraker RT, Kip KE (2001) The amblyopia treatment index. J AAPOS 5:250-254

24. Veenman J, Roelandt T (1994) Onzeker bestaan: De maatschappelijke positie van Turken, Marokkanen, Surinamers en Antillianen in Nederland [An insecure existence, The social position of Turks, Moroccans, Surinamese and Antilleans in The Netherlands]. Boom, Amsterdam

25. Economic Policy Analysis/Netherlands CPB [Central Economic Plan] www.cpb.nl (accessed on 11 August 2009)

26. Fassaert T, Hesselink AE, Verhoeff AP (2009) Acculturation and use of health care services by Turkish and Moroccan migrants: a cross-sectional population-based study. BMC Public Health 9:332

27. Uiters E, Deville WL, Foets M, Groenewegen PP (2006) Use of health care services by ethnic minorities in The Netherlands: do patterns differ? Eur J Public Health 16:388-393

28. Kunst A, Meerding W, Varenik N, Polder J, Mackenbach JP (2007) Sociale verschillen in zorggebruik en zorgkosten in Nederland 2003 [Social inequalities in care consumption and health care costs in the Netherlands 2003]. Rijksinstituut voor Volksgezonheid en Milieu, Bildhoven

29. O'Malley AS, Kerner J, Johnson AE, Mandelblatt J (1999) Acculturation and breast cancer screening among Hispanic women in New York City. Am J Public Health 89:219-227

30. Schnabel P, Bijl R, De Hart J (2008) Betrekkelijke betrokkenheid. Studies in sociale cohesie [Relative commitment. Studies about social cohesion]. Sociaal en Cultureel Planbureau [The Netherlands Insitute for Social Research], Den Haag

31. Gonzalez-Castro JL, Ubillos S (2011) Determinants of psychological distress among migrants from Ecuador and Romania in a Spanish city. Int J Soc Psychiatry 57:30-44

32. Fassaert T, De Wit MA, Tuinebreijer WC, Knipscheer JW, Verhoeff AP, Beekman AT, Dekker J (2011) Acculturation and psychological distress among non-Western Muslim migrants - a population-based survey. Int J Soc Psychiatry 57:132-143

33. Parsons SK, Cruise PL, Davenport WM, Jones V (2006) Religious beliefs, practices and treatment adherence among individuals with HIV in the southern United States. AIDS Patient Care STDs 20:97-111

34. Hjelm K, Bard K, Nyberg P, Apelqvist J (2003) Religious and cultural distance in beliefs about health and illness in women with diabetes mellitus of different origin living in Sweden. Int J Nurs Stud 40:627-643 